\title{
Acute Responses of Gastrointestinal Hormones to Both Oral and Parenteral Intradialytic Nutrition
}

\author{
María José Fernández-Reyes ${ }^{a}$ Rosa Sánchez ${ }^{a} \quad$ Laura García $^{b}$ Cristina Grande ${ }^{c}$ \\ Rosa Codoceo $^{c}$ Manuel Heras $^{a}$ Pedro Iglesias $^{d}$ Sonia Velasco $^{a}$ \\ Alvaro Molina $^{\mathrm{a}}$ Carmen Gutierrez $^{\mathrm{a}}$ Fernando Alvarez-Ude ${ }^{\mathrm{a}}$ \\ Departments of a Nephrology and ${ }^{b}$ Pharmacy, Hospital General de Segovia, Segovia, ' Department of Biochemistry, \\ Hospital Universitario La Paz, and d Department of Endocrinology, Hospital Ramón y Cajal, Madrid, Spain
}

\section{Key Words}

Hemodialysis • Intradialytic nutrition • Ghrelin • Insulin •

Glucagon-like peptide 1

\begin{abstract}
Introduction: Intradialytic nutrition (IDN) has been used to improve the nutritional status of malnourished hemodialysis (HD) patients. Objective: To evaluate the different effects of parenteral IDN (IDPN) and oral IDN (IDON) on nutritionrelated gastrointestinal hormones. Patients and Methods: Seven clinically stable HD patients with malnutrition were included. All patients were treated for 1 month with either IDPN or IDON, with a 4-week period of no nutritional support between each type of therapy. On the first day of each nutritional support (IDON or IDPN) we analyzed the acute responses of insulin, ghrelin, and glucagon-like peptide 1 (GLP1). We compared the areas under the secretory curves (AUC) and the maximum peaks of serum glucose, insulin, ghrelin, and GLP-1. A group of 6 clinically stable HD patients without any type of IDN served as the control group. Results: The acute responses of glucose and insulin to IDN were significantly higher with IDPN than with IDON. The AUC of glucose (602 \pm 81 vs. $495 \pm 81 \mathrm{mg} / \mathrm{dl} / \mathrm{h}, \mathrm{p}<0.01)$ and insulin $(232 \pm$ 103 vs. $73.8 \pm 69 \mu \mathrm{U} / \mathrm{ml} / \mathrm{h}, \mathrm{p}<0.01$ ) as well as the maximum
\end{abstract}

peaks of glucose $(228 \pm 41$ vs. $177 \pm 47 \mathrm{mg} / \mathrm{dl}, \mathrm{p}<0.05)$ and insulin (104 \pm 46 vs. $29 \pm 24 \mu \mathrm{U} / \mathrm{ml}, \mathrm{p}<0.01)$ were significantly higher after IDPN than after IDON. Ghrelin decreased after both IDPN and IDON; however, the decrease was significantly higher with IDPN compared to IDON. The ghrelin nadir was significantly lower in IDPN than in IDON (0.77 \pm 0.5 vs. $1.5 \pm 0.3, p<0.05$ ) although the AUC of ghrelin was not significantly different. GLP-1 was significantly increased at $1 \mathrm{~h}$ after starting both IDPN and IDON with no significant differences between the groups. Conclusion: IDPN induces a higher increase in serum glucose and insulin levels and a greater reduction in serum ghrelin concentrations compared with an equivalent orally administered nutritional supplement.

Copyright $\odot 2010$ S. Karger AG, Basel

\section{Introduction}

Malnutrition is highly prevalent among patients on chronic hemodialysis (HD) and represents a consistent predictor of poor survival in this population [1]. A decreased dietary caloric-protein intake due to anorexia associated with chronic renal failure (CRF), HD-related protein catabolism, intercurrent illnesses, and endocrine

\section{KARGER}

Fax +41613061234 E-Mail karger@karger.ch www.karger.com

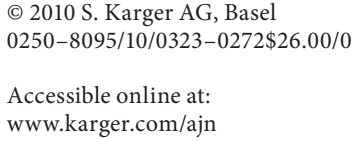

María José Fernández-Reyes

Department of Nephrology, Hospital General de Segovia

Carretera de Avila s/n

ES-40002 Segovia (Spain)

Tel. +3492141 9170, Fax +3492141 9169, E-Mail jfernandezre@ saludcastillayleon.es 
disorders are the main reasons for protein-energy wasting (PEW) in these patients [2]. The available evidence suggests that nutritional supplementation, administered either orally or parenterally, is effective in the treatment of maintenance dialysis patients with PEW in whom the oral dietary intake from regular meals cannot maintain an adequate nutritional status [3]. The advantages of the intradialytic administration of nutritional supplements (oral or parenteral) include proven efficacy and compliance. Intradialytic parenteral nutrition (IDPN) has been shown to improve the energy and protein balance, the albumin synthesis rate, and nutritional parameters [4]. However, IDPN is an expensive and unphysiological form of therapy; moreover, a recent report showed that IDPN did not improve survival in malnourished HD patients compared with oral nutritional supplements [5]. Another report showed that both intradialytic oral nutrition (IDON) and IDPN improved skeletal muscle protein homeostasis after the HD phase in muscle protein metabolism, but the anabolic benefits of IDON persisted postHD whereas those of IDPN disappeared [6]. Oral nutritional supplementation is potentially more physiological and, to our knowledge, there are no studies in which the different effects of both IDPN and IDON on nutritionrelated gastrointestinal hormones have been studied. The aim of the present study was to analyze the acute effects of both forms of intradialytic nutrition (IDPN and IDON) on the serum levels of several nutrition-related gastrointestinal hormones such as insulin, ghrelin - a potent orexigenic with adipogenic properties that favors nutrient intake and weight gain [7] - and glucagon-like peptide 1 (GLP-1) which participates in hydrocarbonate metabolism. This study is part of a research project designed to evaluate the efficacy and tolerability of different nutritional strategies used in malnourished dialysis patients, such as IDON, IDPN, nutritional domiciliary supplements, and dietary recommendations.

\section{Material and Methods}

\section{Patients}

We performed a nutritional assessment of the 32 clinically stable patients on chronic HD in our dialysis unit. The following studies were performed on every patient: (1) a dietary survey of 3 consecutive days; (2) anthropometric measurements, i.e. body mass index (BMI), arm circumference, arm muscle circumference, and triceps skinfold; (3) bioelectrical impedance vector analysis (Vectorial BIA 101 measuring resistance, reactance, phase angle, fat mass percentage, and body cell mass index; Akern, Florence, Italy), and (4) biochemical data related to nutritional status (serum levels of albumin, prealbumin, cholesterol, and transferrin). Mal-
Table 1. Demographic, clinical, and nutritional characteristics of the study population

\begin{tabular}{lccl}
\hline & $\begin{array}{l}\text { Treatment } \\
\text { group } \\
\text { (IDON }+ \\
\text { IDPN) }\end{array}$ & $\begin{array}{l}\text { Control } \\
\text { group } \\
\text { (fasting) }\end{array}$ & $\begin{array}{l}\text { Signifi- } \\
\text { cance } \\
\text { level }\end{array}$ \\
\hline Patients, $n$ & 7 & 6 & - \\
Age, years & $78.6 \pm 5.2$ & $76.6 \pm 4.1$ & NS \\
Time on dialysis, months & $70.1 \pm 51.0$ & $56.1 \pm 42.0$ & NS \\
Kt/V & $1.76 \pm 0.27$ & $1.53 \pm 0.26$ & NS \\
Charlson's comorbidity index & $9(6-11)$ & $8(6-11)$ & NS \\
Body weight, kg & $53.6 \pm 13.7$ & $59.4 \pm 8.9$ & NS \\
BMI & $22.5 \pm 4.8$ & $24.1 \pm 3.6$ & NS \\
Arm muscle circumference, cm & $21.1 \pm 2.4$ & $23.7 \pm 1.0$ & NS \\
Triceps skinfold, mm & $13.9 \pm 5.9$ & $11.8 \pm 3.4$ & NS \\
Phase angle, degrees & $3.3 \pm 1.2$ & $3.1 \pm 0.7$ & NS \\
BCMI & $6.1 \pm 2.3$ & $5.6 \pm 1.1$ & NS \\
Fat mass, \% & $26.4 \pm 4.4$ & $32.7 \pm 11.0$ & NS \\
Caloric intake & & & \\
$\quad$ kcal/kg ideal body weight & $25 \pm 6$ & $24 \pm 3$ & NS \\
Protein intake & & & \\
$\quad$ g/kg ideal body weight & $0.98 \pm 0.26$ & $0.92 \pm 0.36$ & NS \\
\hline
\end{tabular}

Results are presented as means \pm SD or medians (percentile 25-75). BCMI = Body cell mass index.

nutrition, defined following the Kidney Disease Outcome Quality Initiative (K/DOQI) Nutritional Guidelines [8], was present if serum albumin $<4 \mathrm{~g} / \mathrm{dl}$, serum prealbumin $<20 \mathrm{mg} / \mathrm{dl}$, serum cholesterol $<150 \mathrm{mg} / \mathrm{dl}$, and serum transferrin $<150 \mathrm{mg} / \mathrm{dl}$. We also included patients with a normalized protein catabolic rate (nPCR) $<0.8 \mathrm{~g} / \mathrm{kg} /$ day and a caloric intake $<20 \mathrm{kcal} / \mathrm{kg} /$ day. We selected 7 malnourished HD patients and confirmed that they also met the PEW criteria as defined by the International Society of Renal Nutrition and Metabolism (ISRNM) [2] in order to be included in the study. Another group composed of $6 \mathrm{HD}$ patients meeting the PEW criteria served as control group. Exclusion criteria were: active infectious disease, hospitalization within the last 3 months, $\mathrm{Kt} / \mathrm{V}<1.4$ or malabsorptive disease, and insulin-treated diabetes. Comorbidity was assessed using Charlson's comorbidity index as modified by Beddhu [9]. The dialysis dose was estimated using the $\mathrm{Kt} / \mathrm{V}$ Daugirdas II formula and protein ingestion was determined by calculating the protein catabolic rate normalized to actual body weight (nPCR). Written informed consent was obtained from all patients and the study was approved by our local ethics committee. Baseline clinical and demographic characteristics of the patients studied are shown in table 1.

\section{Design and Protocol}

We analyzed the acute responses of gastrointestinal hormones (insulin, ghrelin, and GLP-1) to both IDON and IDPN (treatment group) in 7 malnourished HD patients. These responses were also compared with those obtained in a group of 6 malnourished HD patients who were in a fasted state during dialysis (control group) (table 1). In the treatment group there was a period of 1 month 
with no nutritional supplements between the 2 tests. In each test we obtained blood samples before initiating the administration of the nutritional supplements and then hourly for $3 \mathrm{~h}$ to analyze the acute responses of glucose, insulin, ghrelin, and GLP-1 to nutritional supplements. In order to evaluate the effect of dialysis on gastrointestinal hormone responses, these same tests were performed in a group of 6 malnourished HD patients (control group) who remained in a fasted state during dialysis.

Patients were instructed to come to the HD session after having fasted for at least $6 \mathrm{~h}$. During each test, every patient was dialyzed with biocompatible high flux membranes (Polyflux $210 \mathrm{H}^{\circledR}$, polyamide $2.1 \mathrm{~m}^{2}$; Gambro) for $270 \mathrm{~min}$ with a blood flow of 400 $\mathrm{ml} / \mathrm{min}$ and a dialysate flow of $500 \mathrm{ml} / \mathrm{min}$. The dialysate composition was identical in both cases and consisted of $138 \mathrm{mEq} / \mathrm{l}$ sodium, $2 \mathrm{mEq} / \mathrm{l}$ potassium, $3 \mathrm{mEq} / \mathrm{l}$ calcium, $100 \mathrm{mg} / \mathrm{dl}$ glucose, and $39 \mathrm{mEq} / \mathrm{l}$ bicarbonate. In the IDPN test, IDPN administration started $30 \mathrm{~min}$ after HD initiation and continued until the end of $\mathrm{HD}, 4 \mathrm{~h}$ later. In the IDON test, oral intradialytic supplementation was divided into 4 equal doses $(50 \mathrm{ml}=229 \mathrm{kcal})$; the first dose was administered 30 min after HD initiation and every hour thereafter. IDPN was prepared by our hospital's pharmacy department, mixing the different components in a vertical laminar flow cabinet. It was infused at a rate of $300 \mathrm{ml} / \mathrm{h}$ (approximately $258 \mathrm{kcal} / \mathrm{h}$ ). IDON was prepared, in an attempt to match its composition with that of IDPN, from a specific product designed for HD patients. The composition of both IDON and IDPN is shown in Appendix 1.

\section{Sample Management and Laboratory Methods}

Blood samples for glucose, insulin, ghrelin, and GLP-1 were collected just before intradialytic nutrition and 60, 120, and 180 min after starting intradialytic nutrition. Serum concentrations of interleukin-6, growth hormone, and insulin growth factor-1 (IGF-1) were also quantified at time 0 . All blood samples were immediately centrifuged, separated, and frozen at $-80^{\circ} \mathrm{C}$. All hormones were determined using specific commercial methods as follows: (1) Serum insulin was quantified using a 2-site immunoenzymometric assay which was performed entirely in an AIAPACK (Tosoh Bioscience, USA). The intra- and interassay coefficients of variation were 1.7 and 3.3\%, respectively. The sensitivity of the assay was $1 \mu \mathrm{U} / \mathrm{ml}$, and the normal value was $<17 \mu \mathrm{U} /$ ml. (2) Serum GLP-1 [7-36] was quantified using a commercial enzyme immunoassay kit (DRG International, USA). The intraand interassay coefficients of variation were $<5$ and $<14 \%$, respectively, and the sensitivity of the assay was $0.10 \mathrm{ng} / \mathrm{ml}$. (3) Serum total ghrelin was measured by radioimmunoassay (RIA; 125-Ghrelin; Linco Research, Inc., St. Louis, Mo., USA). The sensitivity of the assay was $0.093 \mathrm{ng} / \mathrm{ml}$ and the normal range was $0.9-2.5 \mathrm{ng} / \mathrm{ml}$. (4) Serum IL-6 was quantified using a commercial enzyme immunoassay kit (DRG, Marburg, Germany). The sensitivity of the assay was $2 \mathrm{pg} / \mathrm{ml}$ and the normal range was $0-17 \mathrm{pg} /$ ml. (5) Serum growth hormone concentrations were determined using an automated RIA (Immunotech S.A.S.). The normal value was $<5 \mathrm{ng} / \mathrm{ml}$. (6) Serum IGF-1 concentrations were determined using an automated RIA (Immunotech S.A.S.). The normal range was $45-406 \mathrm{ng} / \mathrm{ml}$.

\section{Statistical Analysis}

Results are expressed as means \pm SD for normally distributed data and as medians (interquartile range) for nonparametric data.
Table 2. Baseline plasma hormonal and nutrition-elated biochemical parameters before IDON and IDPN tests

\begin{tabular}{lccc}
\hline & $\begin{array}{l}\text { IDON } \\
\text { group }\end{array}$ & $\begin{array}{l}\text { IDPN } \\
\text { group }\end{array}$ & $\begin{array}{l}\text { Control } \\
\text { group }\end{array}$ \\
\hline Glucose, $\mathrm{mg} / \mathrm{dl}$ & $124 \pm 33$ & $126.7 \pm 38.7$ & $91.2 \pm 21^{\mathrm{a}, \mathrm{b}}$ \\
Insulin, $\mu \mathrm{U} / \mathrm{ml}$ & $20.1 \pm 12$ & $18.7 \pm 17$ & $5.8 \pm 3.2^{\mathrm{a}, \mathrm{b}}$ \\
HOMA & $6.1 \pm 5.1$ & $5.8 \pm 7.3$ & $1.4 \pm 1.1^{\mathrm{a}, \mathrm{b}}$ \\
Albumin, g/dl & $3.4 \pm 0.5$ & $3.3 \pm 0.2$ & $3.5 \pm 0.5$ \\
Prealbumin, mg/dl & $20.1 \pm 16.0$ & $20.3 \pm 6.3$ & $23.6 \pm 3.2$ \\
Cholesterol, mg/dl & $122.0 \pm 25.0$ & $128.7 \pm 19.5$ & $148.1 \pm 25.6$ \\
Transferrin, mg/dl & $147 \pm 16$ & $146 \pm 33$ & $\mathrm{NA}$ \\
Ghrelin, ng/ml & $2.5 \pm 0.8$ & $2.1 \pm 1.7$ & $3.9 \pm 2.9$ \\
GLP-1, ng/ml & $0.6 \pm 0.2$ & $0.8 \pm 0.4$ & $0.6 \pm 0.1$ \\
Growth hormone, ng/ml & $2.2 \pm 1.7$ & $3.2 \pm 3.9$ & $2.4 \pm 1.5$ \\
IGF-1, ng/ml & $90.1 \pm 64.0$ & $92.5 \pm 62.0$ & $48.3 \pm 28.2$ \\
Interleukin-6, pg/ml & $79.4 \pm 97.0$ & $35.2 \pm 27.0$ & $\mathrm{NA}$ \\
\hline
\end{tabular}

$\mathrm{NA}=$ Not available. ${ }^{\mathrm{a}} \mathrm{p}<0.05$, IDON vs. control; ${ }^{\mathrm{b}} \mathrm{p}<0.05$, IDPN vs. control.

All comparisons were based on univariate nonparametric tests. Comparisons within groups (change vs. baseline value in both IDPN and IDON) were based on Wilcoxon's test. Comparisons between groups were conducted by fitting a linear regression to the repeated measures in each group and by comparing the slopes of the corresponding regression lines (post hoc Bonferroni test). To compare the means of both groups (the same patients) at different points on the curve we used the Mann-Whitney U test. Numeric correlations were analyzed using Spearman's correlation test. The areas under the secretory curves (AUC) were analyzed using the trapezoidal method. $\mathrm{p}<0.05$ was considered statistically significant. SPSS 11.0 software was used for the statistical analysis.

\section{Results}

\section{Baseline Nutritional and Hormonal Levels}

The baseline levels of the different hormones and nutrition-related biochemical parameter tests were similar in the IDON and IDPN groups (table 2). Baseline glucose and insulin levels in the treatment group (IDON and IDPN) were significantly increased compared to those of the control group (table 2).

\section{Insulin, Ghrelin, and GLP-1 Responses}

Serum glucose and insulin levels significantly increased after starting IDPN and remained high throughout the entire test (fig. 1a, b). However, IDON was followed by a significant increase in serum glucose at 120 min, and serum insulin levels remained stable (fig. $1 \mathrm{a}, \mathrm{b}$ ). 


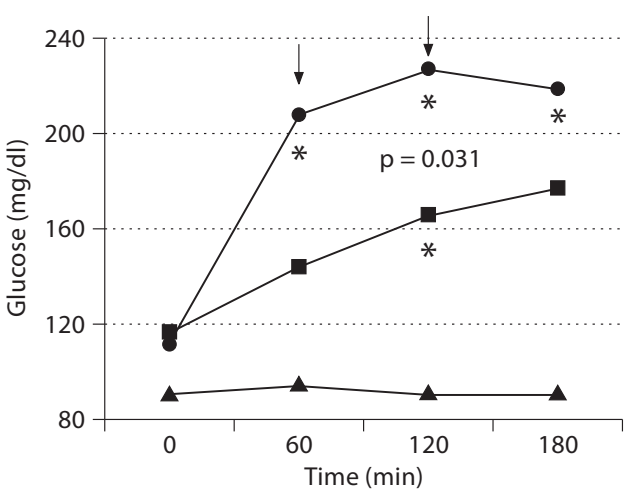

IDPN vs. IDON, $p=0.031$

a IDPN and IDON vs. control, $\mathrm{p}<0.001$

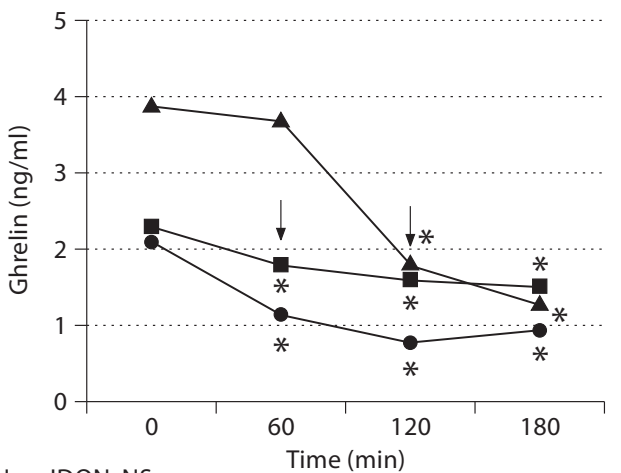

IDPN vs. IDON, NS

IDPN vs. control, $\mathrm{p}=0.047$

c IDON vs. control, NS

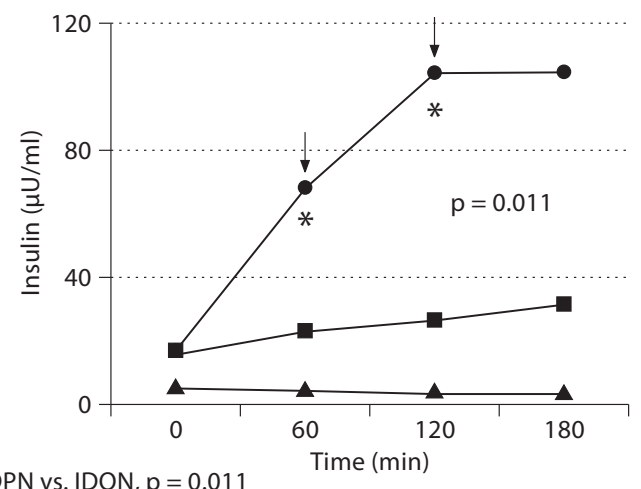

IDPN vs. IDON, $\mathrm{p}=0.01$

IDPN vs. control, $p=0.001$

- IDPN

- IDON

- Control

b IDON vs. control, NS

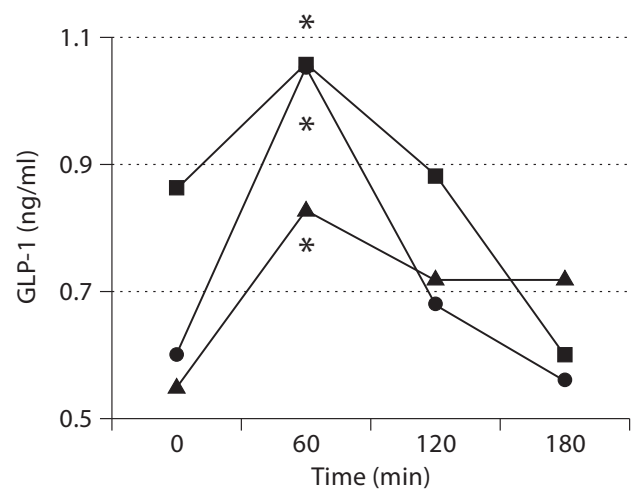

d IDPN vs. IDON or control, NS

Fig. 1. Serum glucose (a), insulin (b), ghrelin (c), and GLP-1 (d) responses to IDPN, IDON, and fasting (control group) during the HD session. ${ }^{*} p<0.05$ vs. baseline; $\downarrow$ indicates that $p<0.05$, IDPN vs. IDON. The results of Bonferroni's test for the corresponding slopes of the regression lines between study groups are shown at the bottom of each figure.

When we compared both groups by fitting a linear regression to the repeated measures and the slope of the corresponding regression lines we found significant differences in both serum glucose and insulin responses. Control patients did not show any change in glucose and insulin concentrations during the HD session (fig. 1a, b).

There was a statistically significant reduction in ghrelin levels during both tests (IDPN and IDON) (fig. 1c); however, this reduction was more pronounced at 60 and $120 \mathrm{~min}$ in the IDPN group compared to the IDON group (fig. 1c). Ghrelin also decreased in the control group from $120 \mathrm{~min}$ on. When we compared the slopes of the curves using the Bonferroni test, we found that the decline in ghrelin was similar in the IDON and IDPN groups and significantly higher in the control group than in the IDPN group; there were no differences between the IDON and control groups (fig. 1c).

Table 3 shows the AUC and the maximum glucose and hormone peaks with IDON and IDPN. The AUC of glucose $(602 \pm 81$ vs. $495 \pm 81 \mathrm{mg} / \mathrm{dl} / \mathrm{h}, \mathrm{p}<0.01)$ and insulin $(232 \pm 103$ vs. $73.8 \pm 69 \mu \mathrm{U} / \mathrm{ml} / \mathrm{h}, \mathrm{p}<0.01)$ as well as the maximum peaks of glucose $(228 \pm 41$ vs. $177 \pm$ $47 \mathrm{mg} / \mathrm{dl}, \mathrm{p}<0.05)$ and insulin (104 \pm 46 vs. $29 \pm 24 \mu \mathrm{U} /$ $\mathrm{ml}, \mathrm{p}<0.01)$ were significantly higher after IDPN than after IDON. The ghrelin nadir was significantly lower in IDPN than in IDON ( $0.77 \pm 0.5$ vs. $1.5 \pm 0.3, p<0.05)$; however, the AUC of ghrelin was not significantly different. 
Table 3. AUC and maximum peaks of glucose, insulin, ghrelin, and GPL-1 during IDON and IDPN

\begin{tabular}{lclc}
\hline & $\begin{array}{l}\text { IDON } \\
\text { group }\end{array}$ & $\begin{array}{l}\text { IDPN } \\
\text { group }\end{array}$ & $\begin{array}{l}\text { Control } \\
\text { group }\end{array}$ \\
\hline AUC of glucose, $\mathrm{mg} / \mathrm{dl} / \mathrm{h}$ & $495 \pm 87$ & $602 \pm 81^{* *}$ & $278 \pm 46^{\S \S, \mathrm{b}}$ \\
AUC of insulin, $\mu \mathrm{U} / \mathrm{ml} / \mathrm{h}$ & $73.8 \pm 69$ & $232 \pm 103^{* *}$ & $12.9 \pm 4^{\S, \mathrm{b}}$ \\
AUC of ghrelin, $\mathrm{ng} / \mathrm{ml} / \mathrm{h}$ & $5.3 \pm 1.2$ & $3.4 \pm 2.3$ & $8.2 \pm 3.7^{\mathrm{a}}$ \\
AUC of GLP-1, ng/ml/h & $3.0 \pm 1.1$ & $2.3 \pm 0.9$ & $2.2 \pm 0.3$ \\
Max. glucose, $\mathrm{mg} / \mathrm{dl}$ & $177 \pm 47$ & $228 \pm 41^{*}$ & $95 \pm 17_{\S \S \S, \mathrm{c}}$ \\
Max. insulin, $\mu \mathrm{U} / \mathrm{ml}$ & $29 \pm 24$ & $104 \pm 46^{* *}$ & $6 \pm 3 \S \S, \mathrm{c}$ \\
Min. ghrelin, $\mathrm{ng} / \mathrm{ml}$ & $1.5 \pm 0.3$ & $0.77 \pm 0.5^{* *}$ & $1.3 \pm 1.0$ \\
Max. GLP-1, ng/ml & $1.01 \pm 0.5$ & $1.06 \pm 0.5$ & $0.83 \pm 0.2$ \\
\hline
\end{tabular}

${ }^{*} \mathrm{p}<0.05 ;{ }^{* *} \mathrm{p}<0.01$, IDPN vs. IDON; ${ }^{\S} \mathrm{p}<0.05 ;{ }^{\S} \mathrm{p}<0.01$; $\S \S \S \mathrm{p}<0.001$, IDON vs. control; ${ }^{\mathrm{a}} \mathrm{p}<0.05 ;{ }^{\mathrm{b}} \mathrm{p}<0.01,{ }^{\mathrm{c}} \mathrm{p}<0.001$, IDPN vs. control.

\section{Correlation Study}

Baseline ghrelin levels were not correlated with the resistance to insulin estimated indirectly by the Homeostasis Model Assessment (HOMA) score [plasma insulin $(\mu \mathrm{IU} / \mathrm{ml}) \times$ plasma glucose $(\mathrm{mmol} / \mathrm{l}) / 22.5]$ or with the maximum peak levels of glucose and insulin at any time. After IDPN we found a significant correlation between ghrelin and HOMA ( $1 \mathrm{~h}: \mathrm{r}=-0.77, \mathrm{p}=0.07 ; 2 \mathrm{~h}: \mathrm{r}=-0.60$, $\mathrm{NS}$, and $3 \mathrm{~h}: \mathrm{r}=-0.82, \mathrm{p}=0.023)$ and, mainly, between ghrelin and insulin levels $(1 \mathrm{~h}: \mathrm{r}=-0.94, \mathrm{p}=0.001 ; 2 \mathrm{~h}$ : $\mathrm{r}=-0.60$, NS, and $3 \mathrm{~h}: \mathrm{r}=-0.7, \mathrm{p}=0.05)$, but there was no correlation with glucose levels. Ghrelin did not correlate with HOMA, glucose, or insulin at any time after IDON.

Ghrelin levels were not correlated with comorbidity, caloric and protein intake, or dialysis dose, but they were negatively correlated with $\mathrm{BMI}(\mathrm{r}=-0.85, \mathrm{p}=0.01)$ and the percentage of fat mass $(\mathrm{r}=-0.93, \mathrm{p}=0.003)$.

We did not find any correlation between glucose or insulin levels and GLP-1 at the beginning or at any of the points on the curve.

\section{Discussion}

The main findings of the present study were: (1) IDPN was associated with a sustained increase in both glucose and insulin. (2) IDPN suppressed serum ghrelin levels more significantly than IDON did. (3) The incretin effect disappeared during the HD session as the administration of equivalent amounts of glucose produced a greater in- sulin response after intravenous glucose administration compared to oral glucose. (4) GLP-1 increased during the HD session regardless of whether the patient had intradialytic nutritional supplements or remained fasting.

Intradialytic nutrition has been proposed as a way to supply nutrients and to reverse catabolic processes. IDPN has been shown to acutely improve nutritional parameters, but a decrease in morbidity and mortality with IDPN compared with patients that only used oral supplementation has not been demonstrated [5]. IDPN has been classically used because of it ability to supply, in a short period of time, a high quantity of nutrients taking advantage of the venous access of HD; but the majority of dialysis patients with PEW do not have any digestive problems that prevent them from using the oral route and, nowadays, we have nutritional supplements specifically designed for them. Our data appear to confirm that the oral route could be more physiological. The carbohydrate load was similar during IDPN (125 g) and IDON (116 g) for 4 h; however, during IDPN administration we found an important increase in glycemia and insulinemia in the first hour which was maintained throughout the dialysis session, even in spite of the use of a dialysate with $100 \mathrm{mg}$ glucose. Contrarily to IDPN, IDON was not followed by significant changes in insulin levels and only a significant increase in glycemia was observed in relation to its basal value at $2 \mathrm{~h}$; in fact, the maximum peak level of glycemia was $177 \pm 37$ $\mathrm{mg} / \mathrm{dl}$ with IDON versus $228 \pm 42 \mathrm{mg} / \mathrm{dl}$ with IDPN ( $\mathrm{p}<$ 0.05 ). The large increase in blood glucose with IDPN indicates an inability of the organism to adequately metabolize an intravenous overload of glucose despite of a considerable increase in insulinemia. This finding could be deleterious. Hyperglycemia could have negative effects via any combination of the following mechanisms: (1) increased generation of reactive oxygen species and activation of the inflammation cascade [10]; (2) direct toxic effects of glucose overload on cells, including immune system cells, and (3) impairment of the body's ability to resist infection [11]. Lastly, it is possible that an intermittent hyperinsulinemia for 3-4 h every 2 days might be associated with several negative metabolic effects.

Ghrelin is a small peptide [28 amino acids (AA); 3,300 $\mathrm{Da}$ ] with orexigenic and adipogenetic properties [7]. The role of ghrelin in the pathogenesis of anorexia in CRF has not been established. In dialysis patients, levels of total ghrelin are increased [12-14]. In normal individuals, plasma ghrelin levels increase after fasting and acutely decrease after a meal [15], supporting the notion that ghrelin has a feedback mechanism related to appetite; in peritoneal dialysis patients such ghrelin suppression is 
blunted [16]. In our study, ghrelin diminished after both IDON and IDPN, which could be partly due to ghrelin dialysis clearance; in fact, Chang et al. [17] observed a diminution of plasma ghrelin at the initiation of HD that reached a maximum after $2 \mathrm{~h}$ with a slight rebound afterwards. Our data from the control subjects confirm that ghrelin decreases during an HD session; this is possibly due to its clearance. Nevertheless, it should be stressed that the ghrelin reduction was significantly greater with IDPN than with IDON or the controls; therefore, such a diminution cannot be attributed only to ghrelin clearance during dialysis. In normal individuals ghrelin secretion is suppressed by either intravenous or oral glucose administration; this decrease could be mediated, at least in part, by changes in plasma glucose and/or insulin $[15,18,19]$. We did not find a correlation between basal HOMA and ghrelin, but in IDPN ghrelin levels were significantly correlated for most of the times on the curve with insulin and HOMA, suggesting that the ghrelin reduction is part of a hormonal response to an insulin increase. In the case of IDON and the controls, ghrelin diminution did not correlate with glucose or insulin, so we think that this was probably due to a local stimulus of gastric cells induced by the meal or simply by the effect of dialysis ghrelin clearance. In our study, we found no correlation between basal total ghrelin levels and the daily intake estimated by the dietary survey; this is probably because in this report we determined levels of total, but not acylated, ghrelin (active peptide). Other authors have found a relationship between total ghrelin levels and appetite in peritoneal dialysis patients [20], and a recent report has proven that exogenous ghrelin could increase appetite in anorexic patients with dialysis [21].

GLP-1, an intestinal peptide [30, 31] (AA) secreted by neuroendocrine cells of the terminal ileum in response to nutrient ingestion, increases rapidly (within 5-10 min) after oral intake, basically by direct contact of the meal with the intestinal mucosa but also by neural and endocrine signals [22]. GLP-1 acts as an incretin to lower plasma glucose by stimulating insulin synthesis and secretion from islet $\beta$ cells and by reducing glucagon release from islet alpha cells. GLP-1 also inhibits gastric emptying and acid secretion [23] and increases satiety, and it has a neoglucogenic effect on extrapancreatic tissues [24]. Due to all of these effects GLP-1 has been proposed as therapy for type 2 diabetes. We found a significant increase in GLP-1 at 60 min after starting HD in both IDPN and IDON, but also in the controls (fasting patients). Their levels went back to basal values after $2 \mathrm{~h}$ of intradialytic
nutrition.It seems that the initial elevation of GLP-1 could be due to HD per se rather than to the glucose supply. During IDON we observed a precocious elevation of GLP-1 that, paradoxically, was not accompanied by the increase of insulin levels that one could have expected, so it appears as if GLP-1 was not able to stimulate insulin synthesis, i.e. a state of GLP-1 endogenous resistance. We also found that GLP-1 levels remained elevated only for a short period of time during HD in spite of continuous oral or intravenous administration of nutrients, so we suppose that it is possible that GLP-1 is rapidly inactivated since DPP-IV-mediated degradation is almost unaffected by impairments in renal function [25]. It is also possible that, due to the small size of the peptide $[30,31]$ (AA), it could be cleared during HD as was confirmed in the control group. All of these data, and the fact that there is no correlation between GLP-1 and insulin and glucose levels either during IDPN or during IDON, make us think that this peptide probably plays only a small role in the regulation of hydrocarbonate metabolism during intradialytic nutrition. Nevertheless, it has been reported that exogenous GLP-1 administration with parenteral nutrition in patients with normal renal function helps to better control serum glucose [26].

The present study has some limitations. The first one is related to the duration of the tests $(180 \mathrm{~min})$ as the HD session lasts $270 \mathrm{~min}$. However, as is shown in figure 1, major changes occurred between 60 and $120 \mathrm{~min}$. The second limitation is that both tests (IDPN and IDON) were carried out on the same patients, whereas the fasting test was performed in the control group composed of 6 different patients. However, we were able to consider each patient as a self control and the changes obtained in each test (IDPN and IDON) could only be attributed to the intradialytic nutrition type. Finally, although the patients in the control group were malnourished patients with similar demographic characteristics, they presented basal serum glucose and insulin concentrations significantly lower than those found in the treatment group; however, these concentrations remained stable throughout the test.

In conclusion, IDON and IDPN can be used to supply a high quantity of nutrients in a short period of time in malnourished HD patients, but use of the oral route appears to be preferable since IDPN induces higher glucose and insulin levels and a higher suppression of ghrelin. It also appears that in HD patients, endogenous GLP-1 does not play a significant role in the regulation of carbohydrate metabolism during intradialytic nutrition. 


\section{Appendix 1}

IDPN Protocol

(1) AA solution (Syntamin 14) $500 \mathrm{ml} \rightarrow 43.7$ g protein $\rightarrow$ $174.8 \mathrm{kcal}$

(2) Glucose $10 \%(250 \mathrm{ml})+$ glucose $40 \%(250 \mathrm{ml}) \rightarrow 125 \mathrm{~g}$

glucose $\rightarrow 500 \mathrm{kcal}$

(3) Lipofundin $20 \%(200 \mathrm{ml}) \rightarrow 40$ g lipids MCT/LCT $\rightarrow$

$360 \mathrm{kcal}$

(4) $6 \mathrm{IU}$ insulin; final volume $=1,200 \mathrm{ml}$; total $\mathrm{kcal}=$

1,035; nonproteic $\mathrm{kcal} / \mathrm{g} \mathrm{N}_{2}=123$.

Quantitative Composition

$\mathrm{N}_{2}=7 \mathrm{~g}$

Protein $=43.7 \mathrm{~g}$

Glucose $=125 \mathrm{~g}$

Lipids $=40 \mathrm{~g}$

$\mathrm{Cl}=17 \mathrm{mEq}(595 \mathrm{mg})$

Acetate $=34 \mathrm{mEq}$

Phosphate $=3 \mathrm{mEq}(93 \mathrm{mg})$

Osmolarity $=976 \mathrm{mOsm} / \mathrm{l}$.

\section{IDON Protocol}

Composition

Two hundred grams were diluted in $200 \mathrm{ml}$ water $(50 \mathrm{ml}$ for each dose) of a specific dialysis supplement (RENERGY ${ }^{\circledR}$; BioNet Medical) that contained $918 \mathrm{kcal}$ and consisted of $40 \mathrm{~g} \mathrm{AA}, 31.2 \mathrm{~g}$ lipids, and $116.4 \mathrm{~g}$ carbohydrates. Each dose $(50 \mathrm{ml})$ contained $229 \mathrm{kcal}$.

\section{Acknowledgments}

This study is part of a research project designed to evaluate the efficacy and tolerability of different nutritional strategies used in malnourished dialysis patients. It was supported by a public research grant from the Junta de Castilla y León (Sacyl), Spain. The economic aid was utilized for laboratory tests but the authors did not receive financial support and have no conflicts of interest.

\section{References}

1 Pifer TB, McCullough KP, Port FK, et al: Mortality risk in hemodialysis patients and changes in nutritional indicators: DOPPS. Kidney Int 2002;62:2238-2245.

- 2 Fouque D, Kalantar-Zadeh K, Kopple J, et al: A proposed nomenclature and diagnostic criteria for protein-energy wasting in acute and chronic kidney disease. Kidney Int 2008;73: 391-398.

-3 Ikizler TA: Nutrition support for the chronically wasted or acutely catabolic chronic kidney disease patient. Semin Nephrol 2009;29: 75-84.

-4 Pupim LB, Flakoll PJ, Brouillete JR, Levenhagen DK, Hakim RM, Ikizler TA: Intradialytic parenteral nutrition improves protein and energy homeostasis in chronic haemodialysis patients. J Clin Invest 2002;110:483-492.

$\checkmark 5$ Cano N, Fouque D, Roth $\mathrm{H}$, et al: Intradialytic parenteral nutrition does not improve survival in malnourished patients: a 2-year multicentric, prospective, randomized study. J Am Soc Nephrol 2007;18:2583-2591.

-6 Pupim LB, Majchrzak KM, Flakoll PJ, Ikizler TA: Intradialytic oral nutrition improves protein homeostasis in chronic haemodialysis patients with deranged nutritional status. J Am Soc Nephrol 2006;17:3149-3157.

7 Ghigo E, Broglio F, Arvat E, Macario M, Papoti M, Muccioli G: Ghrelin: more than a natural GH secretagogue and/or an orexigenic factor. Clin Endocrinol (Oxf) 2005;62:1-17.

8 Fouque D, Vennegoor M, Wee PT, et al: EBPG guideline on nutrition. Nephrol Dial Transplant 2007;22(suppl 2):ii45-ii87.

$\checkmark 9$ Beddhu S, Bruns FJ, Saul M, Seddon P, Zeidel ML: A simple comorbidity scale predicts clinical outcome and cost in dialysis patients. Am J Med 2000;108:609-613.
10 Fiaccadori E, Parenti E, Maggiore U: Nutritional support in acute kidney injury. J Nephrol 2008;21:645-656.

-11 Turina M, Fry DE, Polk HC: Acute hyperglycemia and the innate immune system: clinical cellular and molecular aspects. Crit Care Med 2005;33:1624-1633.

12 Iglesias P, Díez JJ, Fernández-Reyes MJ, et al: Serum ghrelin concentration in patients with chronic renal failure undergoing dialysis. Clinical Endocrinology (Oxf) 2006;64:68-73.

13 Pérez-Fontán M, Cordido F, Rodríguez-Carmona A, et al: Plasma ghrelin levels in patients undergoing haemodialysis and peritoneal dialysis. Nephrol Dial Transplant 2004; 19:2095-2100

14 Yoshimoto A, Mori K, Sugawara A, et al: Plasma ghrelin and desacyl ghrelin concentrations in renal failure. J Am Soc Nephrol 2002; 13:2748-2752.

15 Shiiya T, Nakazato M, Mizuta M, et al: Plasma ghrelin levels in lean and obese humans and the effect of glucose on ghrelin secretion. J Clin Endocrinol Metab 2002;87:240-244.

16 Pérez-Fontán M, Cordido F, Rodríguez-Carmona A, et al: Acute plasma ghrelin levels and leptin response to oral feeding or intraperitoneal hypertonic glucose-based dialysate in patients with chronic renal failure. Kidney Int 2005;68:2877-2885.

17 Chang C, Hung C, Yen C, Hwang K, Lin C: The relationship of plasma ghrelin levels to energy regulation, feeding and ventricular function in non-diabetic haemodialysis patients. Nephrol Dial Transplant 2005;20: 2172-2177.

18 Nakagawa E, Nagaya N, Okumura H, et al: Hyperglucemia suppresses the secretion of ghrelin, a novel growth-hormone-releasing peptide: responses to the intravenous and oral administration of glucose. Clin Sci (Lond) 2002;103:325-328.

19 Saad MF, Bernaba B, Hwu CM, et al: Insulin regulates plasma ghrelin concentration. J Clin Endocrinol Metab 2002;87:3997-4000.

-20 Aguilera A, Cirujeda A, Amair R, et al: Ghrelin plasma levels and appetite in peritoneal dialysis patients. Adv Perit Dial 2004;20:194199.

21 Ashby DR, Ford HE, Wynne KJ, Wren AM, Murphy KG, Busbridge M, Brown EA, Taube DH, Ghatei MA, Tam FW, Bloom SR, Choi P: Sustained appetite improvement in malnourished dialysis patients by daily ghrelin treatment. Kidney Int 2009;76:199-206.

22 Deacon CF: What do we know about the secretion and degradation of incretin hormones? Regul Pept 2005;128:117-124.

23 Drucker D: Biological actions and therapeutic potential of the glucagon-like peptides. Gastroenterology 2002;122:531-544.

24 Acitores A, Gonzalez N, Sancho V, Valverde I, Villanueva-Peñacarrillo ML: Cell signalling of glucagon-like peptide-1 action in rat skeletal muscle. J Endocrinol 2004;180:389398.

25 Meir J, Nauck MA, Kranz D, et al: Secretion, degradation, and elimination of glucagonlike peptide 1 and gastric inhibitory polipeptide in patients with chronic renal insufficiency and healthy control subjects. Diabetes 2004;53:654-662.

26 Nauck MA, Walberg J, Vethacke A, et al: Blood glucose control in healthy subjects and patients receiving intravenous glucose infusion or total parenteral nutrition using glucagon-like peptide 1. Regul Pept 2004;118:8997. 